\title{
FROM PLANNED OBSOLESCENCE TO THE CIRCULAR ECONOMY IN THE SMARTPHONE INDUSTRY: AN EVOLUTION OF STRATEGIES EMBODIED IN PRODUCT FEATURES
}

\author{
Barros, Mário (1); \\ Dimla, Eric (2) \\ 1: Aalborg University; \\ 2: Vietnamese-German University
}

\begin{abstract}
Planned obsolescence can artificially increase sales by stimulating desire or perceived need. This can be done in many ways and some companies are releasing newer models sooner than necessary or engineering the product to fail after a certain amount of use. In recent years, we have observed a change in the pattern of planned obsolescence strategies employed by technological companies, shifting from aesthetic to technological obsolescence. The reaction to this model comes from social enterprises and grassroots movements addressing the circular economy and repairability. This paper illustrates these relationships in context, taking the mobile phone industry as a case study. We focus on product architecture and product features, as a reference point to discuss the embodiment of strategies, and the degree of control the consumer is given for repairing the product. Using netnography as a method to collect data in a digital-mediated environment, this paper highlights how planned obsolescence strategies are embedded in product characteristics and summarises their evolution. It concludes by opposing planned obsolescence strategies to circular economy principles to discuss more sustainable pathways for the smartphone industry.
\end{abstract}

Keywords: Product families, Smartphone, Planned obsolescence, Circular economy, Design process

\section{Contact:}

Barros, Mário

Aalborg University

Department of Architecture, Design \& MediaTechnology

Denmark

mbar@create.aau.dk 


\section{INTRODUCTION}

Planned obsolescence (PO) is the conscious decision taken by a company to produce a product that will become obsolete in a predefined timeframe (Packard, 2011).

The exploration of natural, finite resources and the amount of e-waste define the beginning and the end of an unsustainable relationship with the environment regarding the design and consumption of consumer electronics. The amount of e-waste is increasing and less than $18 \%$ of the e-waste generated in 2019 was collected and recycled (Forti et al., 2020). The waste problem generated by the linear economy and the lack of policies to counteract it has long been acknowledged (King et al., 2006). The circular economy model aims at addressing the mentioned problems from a systemic perspective, taking into account that products must be designed to last longer and business models should encompass repairing, reusing, remanufacturing and recycling as circularity requirements.

In this paper, we select the mobile phone industry as a case study representative of the consumer electronics category. Smartphones have replaced traditional cell phones in similar fashion that IoT is expected to replace traditional consumer electronics. Therefore, by examining this case study, we aim at contributing to a debate about the evolution of consumer electronics. We analyse mobile phones from three different brands that are representative of three periods of the typology evolution: cell phone, smartphone, and modular smartphone. We examine the selected products as tangible examples of the application of PO strategies and a counteracting strategy considering circular economy principles. The goal is to unravel a) how these strategies are embodied in industrial design; b) how they evolve to accommodate for typology and product evolution; and c) how reactions to prevalent PO strategies are developed.

Research has evolved from analysing the consequences of PO strategies from a holistic standpoint (Cooper, 1994; Packard, 2011) to include perspectives of companies (Longmuss and Poppe, 2017) and consumers (Cooper, 2004; Huang and Truong, 2008; Kuppelwieser et al., 2019). Recent studies have addressed how consumers perceive obsolescence in mobile phone cases (Lilley et al., 2016). It is agreed in different cultures that aesthetics is not a key buying driver of smartphones (Lau et al., 2016; Toufani et al., 2017), but rather usefulness, enjoyment, and brand reputation.

The transition from a linear to a circular economy has been addressed from an industrial design perspective, by researchers proposing methods for extending the lifespan of products (Bakker et al., 2014) and guidelines for designing products for the circular economy (Go et al., 2015; Sumter et al., 2017, 2020). So far, research has not compared the evolution of PO strategies against circular economy practices by focusing on the relationship between strategy and product characteristics. The novelty of this paper lies on examining the evolution of PO strategies in the mobile phone industry by analysing specific products. The selected products are representative of practices undertaken by major companies that have a market pull effect, setting up the standards for the behaviour of the market (competitors, consumers, legislation). In order to address the phenomena, firstly we relate the PO strategies with product features, marketing positioning and index of repairability. Secondly, we establish parallels between PO strategies with the linear economy and compare them with circular economy product strategies. Thirdly, by mapping the evolution of these product life strategies we contribute to the debate of sustainability in the consumer electronics industry.

The paper is organised in six sections. The introduction is followed in Section 2 by a theoretical background characterising the study of planned obsolescence and circular economy. Section 3 details the methodology for the case study while Section 4 presents the mobile phone case study, analysing the products. Section 5 discusses the case study, and section 6 concludes the paper by reflecting upon how to achieve higher levels of sustainability in the smartphone industry.

\section{THEORETICAL BACKGROUND}

Planned obsolescence aims at reducing the lifespan of a product to stimulate repeated sales. Packard (2011), who popularised the term and tied it to economic growth, distinguished three main categories of obsolescence: function, quality, and desirability (summarised in Table 1). Obsolescence of function occurs when a new product outperforms an existing one. On the market context, it is characterised by the competition of companies trying to fulfil a need in the best way. On the context of a single company, it can be a strategy encompassing the release of a product in the market while already planning the release of its substitute. 
Obsolescence of quality - also termed technological obsolescence - is when a product stops performing its function due to a faulty or broken component whose life cycle has been deliberately reduced by design. Often, different components of the product deteriorate at different rates and it is frequently difficult to obtain and fit replacement components, with the result that the entire product has to be discarded. Bernard London (1932), who advocated for a reduction in the life cycle of products to stimulate continuous economic growth, is credited as the theorist defining this category of obsolescence. In the context of smartphones, the analysis of technological obsolescence must include software obsolescence (Bartels et al., 2012). Software obsolescence in smartphones can be the result of an update of one software rendering another obsolete, or the termination of technical assistance, or the update of a software that cannot be executed in a certain hardware (Sandborn, 2007).

Obsolescence of desirability - also termed psychological, perceived or aesthetic obsolescence - involves the alteration of superficial characteristics of a product to create a new model, turning the previous version undesirable, thus rendering it obsolete despite its primary function still sound. The new product, perceived as more efficient, is introduced in the market supported by promotional campaigns that communicate and dictate the new fashion. Alfred Sloan (1990) developed this approach in General Motors in the 1920s, with the introduction of annual release of new models. Many of these employed a combination of the same chassis with multiple bodies to creating different models targeting specific segments. The demand for aesthetic change fuelled the rise of streamlining and of industrial design in the United States, meeting the brand ideology that a product must be more attractive than its competitor to guarantee greater sales.

PO incorporates strategies from these categories (summarised in Table 1), with the emphasis on each one being dependent on the type of product and industry in which it operates. The goal is to reduce the time between repeated purchases thus generating long-term sales volume.

Table 1. Overview of planned obsolescence categories.

\begin{tabular}{|l|l|}
\hline Category & Main characteristics \\
\hline Function & $\begin{array}{l}\text { Technology development; Better fulfilment of needs through performance or } \\
\text { features. }\end{array}$ \\
\hline $\begin{array}{l}\text { Quality } \\
\text { (Technological) }\end{array}$ & $\begin{array}{l}\text { Deliberate reduction of the life cycle of a component to render the product } \\
\text { obsolete; Software obsolescence. }\end{array}$ \\
\hline $\begin{array}{l}\text { Desirability } \\
\text { (Aesthetic) }\end{array}$ & $\begin{array}{l}\text { Products with refined aesthetics released in a short time to render the previous } \\
\text { version obsolete. }\end{array}$ \\
\hline
\end{tabular}

Even though PO and linear economy constitute the main paradigm of production, alternative models have been developed for long. The current push towards counteracting such a paradigm can be summarised from two main approaches. A bottom-up one, led by grassroots community-centred organisations and international networks of environmental NGOs (Right to Repair, 2020) demanding more sustainable development. And a top-down one, the circular economy (Webster et al., 2017), encompassing a systemic approach to both product life cycle and business models. By addressing the relationship between environmental resources and the economy and by acknowledging such existence in a closed loop with different tiers, the circular economy has gained momentum not only in academia but also in the industry and policymaking. The European Union (European Commission, 2020) and France have implemented circular economy principles into policymaking. In France, under the bundle of laws addressing waste reduction and the circular economy (MTE, 2021), one of the measures that encompass direct information for consumers is the index of repairability (IOR). From the beginning of 2021, five categories of electronic products, amongst which, smartphones, feature an IOR. The French IOR is a 010 point system (where 10 accounts for maximum ease of repairability) that considers the accessibility of technical documentation, ease of disassembly, availability and price of spare parts, and access to software updates for smartphones. The manufacturer calculates the IOR based on predefined parameters developed by the French Ministry of Environment.

iFixit (2020) firstly developed an index of repairability in 2009 and consulted in the development of the French IOR. In this online platform, users develop repair guides for products in a collaborative and crowdsourced-reviewed way. The score is measured on a $0-10$ point system. The difference between the iFixt IOR and the French IOR is that the former focuses on the ease of disassembling and repairing the product itself, not considering circular economy principles, such as accessibility and price of spare parts in the market. 
General principles for shifting the consumer electronics industry towards the circular economy have been defined (Meloni et al., 2018). These principles include design decisions about hardware, such as designing products that can be adaptable, repaired and/or are easily disassembled for components' recycling. On the issue of software obsolescence, recommendations are made to design more stable operating systems that last longer to reduce hardware obsolescence, and the use of big data to monitor hardware components' life cycle. The same report recommends improvement of the reuse market, achieved by optimising the connectivity amongst consumers and the automation of supporting processes, such as disassembly, sorting and refurbishment.

\section{METHODOLOGY}

To address the question of how PO has evolved in the mobile phone industry and to compare it against circular economy practices, we use the case study methodology. According to Yin (1994), a case study enables the inquiring a "phenomenon within its real-life context".

We identify two successful products from market leaders in specific stages of development of the industry: Nokia and Apple. The third product is the Fairphone, the first modular smartphone released through a social enterprise.

The case studies enable the analysis of the product characteristics as the physical embodiment of product life strategies. We analyse them from an industrial design perspective, focusing primarily on product architecture and product features. From the analysis of these characteristics, we establish the interrelationships with overall strategy, redesign and upgradeability. With insights drawn from inductive reasoning, this study stems from specific to general.

Data collection combined secondary data with netnography (Kozinets, 2009). Netnography is relevant in an environment where digitalization plays an important part. Data is collected directly from the manufacturers' websites and respective online archives, complemented with information from the Internet Archive and GSMArena (2000) phone database. In addition, we analyse the indexes of repairability from iFixit and the French law.

We develop a conceptual model for analysis and comparison, linking several aspects of the literature in order to gain insights to explain the phenomena explored in this paper.

\section{OBSOLESCENCE IN THE MOBILE PHONE INDUSTRY}

\subsection{Evolution of the market}

Mobile phones have significantly evolved since they were developed by Motorola in 1973. The primary function of the mobile phone as a communication device has expanded since its rise in the 1990s and by the turn of the century, different typologies were available in the market. The functionality of mobile phones grew from calling other people through a mobile device, to include sending text messages, and access to other services as cellular networks developed. Because of the decrease of the cost of technologies, mobile phones evolved into multimedia devices, featuring cameras, music players and access to the internet.

\subsection{Nokia and aesthetic obsolescence in mobile phones}

Nokia was the market leader in mobile phones, from 1998 until 2008 (Lamberg et al., 2019). During that period of ascension and as market leader, Nokia consistently used design to innovate its mobile phones' body configurations. The company pioneered new types of usability, some of which addressed very specific target groups and needs, such as controls on both sides for gamers, foldout keyboards for emailing, mobile internet devices, or swivelling devices for ease of camcorder access, for example. The accruing rising number of submitted patents - 315 in 1990 to peak at 6510 in 2008 - indicated their approach to innovation (Bouwman et al., 2014).

The analysis of aesthetic obsolescence in Nokia focuses on the fashion collections released annually between 2004 and 2006. Whilst the release of updated versions of the same models was already an observable pattern, the annual release of a collection and the employment of the word 'fashion' to market the phones reinforced the idea of aesthetic obsolescence. Furthermore, during this period Nokia increased the number of phone releases year on year from 21 models in 2004 to 35 models in 2005, 32 models in 2006 and 41 models in 2007 (Lamberg et al., 2019). The public release of the collection in a fashion event further associated its positioning with a seasonal side of that industry. 
The first fashion collection, released in 2004, interpreted the Art Deco movement through the lens of high tech. It comprised three phones, each featuring a distinctive body configuration and usability. The flagship model, the Nokia 7280 (Figure 1) had a rotator controller as a substitute for input, instead of a numeric keypad. Distinctive characteristics of the collection are the glossy finishes, leather fascia, etched details and mirrored screens.

The 'L'Amour Collection' (the name of the 2005 collection) was presented as 'trend-inspired'. The overall configuration of the phones is similar, except in the swivel phone of the 7370 model. Regarding details, leather fascia, mirrored screens and etched graphics remain as primary elements, with a change on the decorative graphics motives. New camera and music player modules constitute the incremental updates in technology. In 2006, Nokia discontinued and substituted the flagship model and changed colours and updated the cameras in the other models.
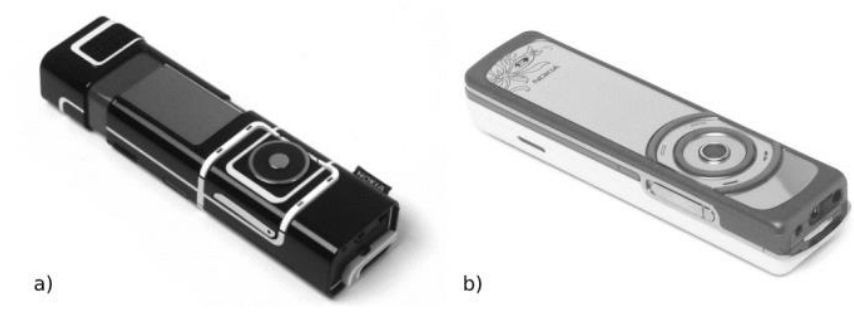

Figure 1. (a) Nokia 7280 model; (b) Nokia 7280 model (L'Amour collection).

Table 2 summarises the how Nokia employed planned obsolescence strategies in this period, with aesthetic being the most important. The strategy of designing products according to annual design trends and relying on marketing techniques that speak to the ephemeral status of the product's appearance defines this approach to aesthetic obsolescence. There is a constructed narrative communicated by advertisement that is based on a sequence of desire and disappointment. In this narrative, social status and high fashion define the aspirational context that the acquisition of the mobile phone will fulfill. The product features, based on strong aesthetics designed in tandem with contemporary trends contributes to a fleeting relationship with the product. A surface redesign paired with an incremental technological improvement, even on secondary functions, renders the previous model obsolete.

Table 2. Summary of planned obsolescence in Nokia.

\begin{tabular}{|l|l|}
\hline Category & Main characteristics \\
\hline Function & Camera update; Music player update. \\
\hline Quality (Technological) & - \\
\hline Desirability (Aesthetic) & $\begin{array}{l}\text { Annual release of models; Fashion-inspired collections; New aesthetic } \\
\text { features following mainstream trends. }\end{array}$ \\
\hline
\end{tabular}

\subsection{Apple and technological obsolescence in smartphones}

Apple disrupted the smartphone market with the iPhone, announced in 2007 and released in 2008 . We can characterise it as a technology epiphany (Verganti, 2011) which results when design-driven innovation overlaps technology push, resulting in both radical improvement of the functionality and the generation of new meanings. The iPhone encapsulated a series of existing technologies in a cohesive product by addressing unsolicited user needs. The approach enabled the creation of new meanings for mobile computing.

The consequence of such innovation strategy was the creation of a new market for smartphones based on a new product typology. Results were a rapid growth of sales, doubling every year from 2008 to 2012 and peaking at 231 million devices sold in 2015 (Statista, 2018).

Apple released one iPhone version annually from 2007-2012. The company introduce a completely new version every two years, with one incremental model released in-between the cycle. In the 20132015 period, the same pattern is observable, however, with two versions released. From 2016 onwards, the pattern changed, with annual launching of new models in different versions. For this reason, our analysis focuses on this last period up to the present (summarised in Table 3).

The analysis of technological obsolescence in Apple iPhone addresses hardware, software and the relationship between the two because the company has full control over the design of both. Apple develops the operating system and the App Store, which is the platform where users can download third- 
party applications. Furthermore, the company controls which third-party applications can feature on the App Store through a closed review system (Lee and Soon, 2017). Research have addressed the issue of consumer dissatisfaction and resistance about this model (Wolk, 2010). To characterise technological obsolescence, we have developed the model shown in Figure 2. There are practices under unique categories of hardware or software, as well as some that belong to both areas, which is firmware.

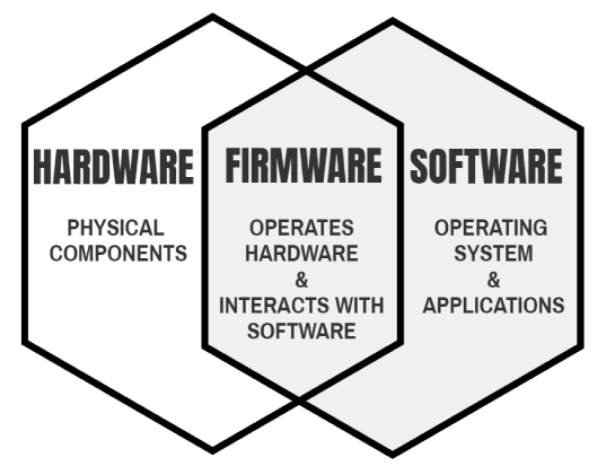

Figure 2. Model of technological obsolescence in the smartphone industry.

Data for analysing technological obsolescence in the hardware of iPhone models comes from iFixit repair guides. Overall, the use of mechanical fasteners instead of glue in several sub-assemblies are the main drivers for iPhones positive repairability index. Nonetheless, the use of a proprietary screw makes repairing by a third-party more complicated and not accessible to a common user. Product architecture decisions that make repair activities more complex include layout of cables slipped under unrelated components creating complex sub-assemblies and glass glued to the chassis that cannot be replaced. The change of battery and the front glass have remained accessible over the redesigns.

Firmware relates to both hardware and software. Firmware enables the configuration and interoperability of hardware components, and is not intended for direct interaction with the user. In this context, Apple uses firmware to limit the product usability in case of unauthorised repairs. This principle has been applied to batteries, and has started to being extended to cameras and displays since 2020. As an example, when battery is replaced, firmware prompts error messages, disables the battery capacity reader and other functions, such as the Face ID reader. Likewise, when the camera is replaced, firmware blocks camera functionality.

Table 3. iPhone releases and repairability index.

\begin{tabular}{|l|l|c|c|c|}
\hline Year & iPhone model & $\begin{array}{c}\text { Number } \\
\text { of } \\
\text { models }\end{array}$ & $\begin{array}{c}\text { Repairability } \\
\text { index (0-10) } \\
{[\text { iFixit }]}\end{array}$ & $\begin{array}{c}\text { Repairability } \\
\text { index (0-10) } \\
{[\text { France] }}\end{array}$ \\
\hline 2016 & iPhone 7, iPhone 7 Plus, iPhone SE & 3 & $7 / 7 / 6$ & $6.7 / 6.6 / 6.2$ \\
\hline 2017 & iPhone 8, iPhone 8 Plus, iPhone X & 3 & 6 & $6.6 / 6.6 / 4.8$ \\
\hline 2018 & iPhone XS, iPhone XS Max, iPhone XR & 3 & 6 & $4.7 / 4.6 / 4.5$ \\
\hline 2019 & iPhone 11, iPhone 11 Pro, iPhone 11 Pro Max & 3 & 6 & $4.6 / 4.6 / 4.5$ \\
\hline 2020 & $\begin{array}{l}\text { iPhone 12, iPhone 12 Pro, iPhone 12 Pro } \\
\text { Max, iPhone SE, iPhone 12 Mini }\end{array}$ & 5 & 6 & 6 \\
\hline
\end{tabular}

Software updates for discontinued iPhones are mandatory to enable users' access to functions such as email and web browsing (Apple, 2019). Furthermore, battery drain issues related with software updates have been confirmed by independent research (Sun et al., 2019).

Table 4 summarises the strategies of PO used by Apple under the three main categories. Technological obsolescence prevails over the other two categories. Furthermore, Apple complements PO with other strategies. The change of the charging cable on the iPhone 12 is categorised under function obsolescence. Coupled with this decision, Apple does not include the charger in the original packaging of the product, thus requiring consumers to buy a separate one.

A complementary practice to technological obsolescence is the legal restriction on repair activities. Apple prevents users and independent repair technicians of repairing their products by not making repair manuals publicly available, limiting access to spare components, not enabling Apple-certified 
independent repairers to own any stock of components, and by taking legal actions against non-Applecertified repairers (Mikolajczak, 2020).

Table 4. Summary of planned obsolescence in Apple

\begin{tabular}{|l|l|l|}
\hline Category & Sub-category & Main characteristics \\
\hline Function & - & $\begin{array}{l}\text { Multiple cameras; New cameras modules; Wireless charging; } \\
\text { Removed headphone jack for exclusive wireless headphones } \\
\text { ecosystem; Better processors; Better displays; Greater storage } \\
\text { capacity; Change of charging cable type. }\end{array}$ \\
\hline $\begin{array}{l}\text { Quality } \\
\text { (Technological) }\end{array}$ & Hardware & $\begin{array}{l}\text { Proprietary screws; Glued components; Complex sub- } \\
\text { assemblies. }\end{array}$ \\
\hline $\begin{array}{l}\text { Quality } \\
\text { (Technological) }\end{array}$ & Firmware & $\begin{array}{l}\text { Error messages and function disability when changing } \\
\text { batteries, cameras, or displays; Update not possible for older } \\
\text { models. }\end{array}$ \\
\hline $\begin{array}{l}\text { Quality } \\
\text { (Technological) }\end{array}$ & Software & $\begin{array}{l}\text { Software updates leading to battery degradation; Mandatory } \\
\text { software updates for accessing basic functions; Discontinuity } \\
\text { of support for older models. }\end{array}$ \\
\hline $\begin{array}{l}\text { Desirability } \\
\text { (Aesthetic) }\end{array}$ & - & Annual release of models; New colors. \\
\hline
\end{tabular}

\subsection{Fairphone and the circular economy in smartphones}

The Fairphone was born in 2010, out of a collaboration between three organizations: a non-profit media lab that develops technology for social innovation; a non-governmental organization focused on the fair distribution of minerals; and a telecommunications company (Wernink and Strahl, 2015). It started as a campaign raising awareness and demanding for fair human and environmental production of mobile phones, evolving into an open source community of specialists designing a mobile phone based on those principles. Its message has been amplified through online communities. After funding from an accelerator program and a crowdfunding campaign preselling mobile phones, the Fairphone 1 was developed and released in the market at the end of 2013.

The strategic design principles address the opening of all steps of the supply chain, from the extraction of minerals to manufacturing and distribution. Concerning strategy, Fairphone collaborates with other associations for recycling and for certifying labour conditions. A direct engagement with other stakeholders, amongst which users and researchers in lifecycle analysis, provides a debate around sourcing, production, distribution, use, reuse, and recycling. As an example, by providing information and direct access to spare components and upgraded modules, the Fairphone enables consumers to repair or upgrade their smartphones.

From the Fairphone 2 onwards, the design is entirely made by the company. Product development encompasses a partnership with iFixit for facilitating repair activities. The product architecture is modular and this principle is applied down to smaller components. This was achieved by changing joining methods, turning integral modules into sub-assemblies that enable the substitution of components. As a result, the latest released models have a score of 10 in the iFixit IOR and a high score in the French IOR, which accounts for the most accessible repairs in the smartphone industry, thereby setting up the standard for good practices regarding hardware repairability (Table 5).

Table 5. Fairphone releases and repairability index.

\begin{tabular}{|c|l|c|c|c|}
\hline Year & Fairphone model & $\begin{array}{c}\text { Number of } \\
\text { models }\end{array}$ & $\begin{array}{c}\text { Repairability index } \\
(0-10)[\text { iFixit] }\end{array}$ & $\begin{array}{c}\text { Repairability index } \\
(0-10)[\text { France] }\end{array}$ \\
\hline 2013 & Fairphone 1 & 1 & 7 & - \\
\hline 2015 & Fairphone 2 & 1 & 10 & - \\
\hline 2019 & Fairphone 3 & 1 & 10 & - \\
\hline 2020 & Fairphone 3+ & 1 & 10 & 8.7 \\
\hline
\end{tabular}

\section{DISCUSSION}

Table 6 summarises the different product life strategies investigated in this paper. Aesthetic obsolescence focuses primarily on style rather than functionality, communicated through advertisement. The consumer 
may buy a new release because of brand loyalty and a commitment to stay updated with the latest trend. Nonetheless, the consumer's decision has a large impact on the brand-consumer relationship, and is up to the consumer to decide on the kind of pattern of consumption he/she wants. This level of selfdetermination decreases when dealing with technological obsolescence.

The reduced lifespan of components, such as the battery, for example, hinders the normal functionality of a smartphone. In the presented case, where Apple has major control over reparation, the cost of replacement may restrict the consumer options even further. Even though the final decision on whether to replace or buy new is up to the consumer, there is pressure for buying a new model, if the difference in cost between repairing and buying a new model is minimal.

Table 6. Summary of product life strategies in the mobile phone industry.

\begin{tabular}{|c|c|l|}
\hline $\begin{array}{c}\text { Product Life } \\
\text { Strategy }\end{array}$ & $\begin{array}{c}\text { Category } \\
\text { / Sub-category }\end{array}$ & Main characteristics \\
\hline \multirow{3}{*}{$\begin{array}{c}\text { Planned } \\
\text { Obsolescence }\end{array}$} & Aesthetic & $\begin{array}{l}\text { Annual model release; Strong aesthetics; Tap into fashion } \\
\text { trends. }\end{array}$ \\
\cline { 2 - 3 } & $\begin{array}{c}\text { Technological / } \\
\text { Hardware }\end{array}$ & $\begin{array}{l}\text { Proprietary screws; Glued components; Complex sub- } \\
\text { assemblies. }\end{array}$ \\
\cline { 2 - 3 } & $\begin{array}{c}\text { Technological / } \\
\text { Firmware }\end{array}$ & $\begin{array}{l}\text { Error messages and function disability when changing } \\
\text { components; Update not possible for older models. }\end{array}$ \\
\cline { 2 - 3 } & $\begin{array}{c}\text { Technological / } \\
\text { Software }\end{array}$ & $\begin{array}{l}\text { Software updates leading to battery degradation; } \\
\text { Mandatory software updates for accessing basic } \\
\text { functions; Discontinuity of support for older models. }\end{array}$ \\
\hline Circular & - & $\begin{array}{l}\text { Modular product architecture; Collaborative } \\
\text { development; Spare parts and repair instructions } \\
\text { available; Recycling programs. }\end{array}$ \\
\hline
\end{tabular}

The consumer's self-determination is even more reduced when facing firmware and software obsolescence. Even though firmware halting components' functionality can be justified for security reasons, such practice limits reparability. Software obsolescence may compromise the functionality of applications. In both cases, the company has the control to plan obsolescence and have remote control through updates. Furthermore, the repair difficulty grows in complexity, even for specialised users or repairers, because the scope is not limited to hardware. In the case of firmware, it requires testing interoperability across components, which requires access to expert knowledge in programming and tools for testing. In the case of software, it requires programming skills and access to software development kits.

The Fairphone counteracts PO through community engagement, product architecture, and access to documentation and spare parts for reparation. Nonetheless, repair activities are made by the consumer, which implies a user with access to tools and willing to spend time performing the task.

When compared with major companies with physical stores and repair centres, the Fairphone has limitations to grow its niche market to other types of users. Despite this, the Fairphone has been pushing for a rethinking about how the smartphone market operates, including a debate for a transition to a circular economy. Its openness creates a chain of effects in the market, exemplified by the independent studies (Joshi and Pargman, 2015; Proske et al., 2016; Wernink and Strahl, 2015) that both report and strengthen its operations, and the emergence of other manufacturers addressing similar design practices and business models.

In Europe, networks of associations advocating for consumers rights to repair their products have been pushing an agenda for longer-lasting products. The French law that includes the IOR as mandatory information for the market introduces requirements for smartphone manufacturers that can have a positive effect towards a circular economy. Nonetheless, the changes manufacturers are required to do relate to the business-to-consumer market, thus being tactical and not transformational. Manufacturers have to release service manuals, update software for longer periods and provide available spare parts to the market. Considering the four tiers of the circular economy - repair, reuse, remanufacture and recycle - manufacturers have to cope with the first. Transformational changes would require manufacturers having to address the remaining tiers. This would encompass developing takeback systems, accessing relationships with independent repairers, establishing maximum delivery times for spare parts, designing for disassembly to facilitate recycling, among other decisions that would affect both the industrial design 
of smartphones and respective business models. Despite these questions, the inclusion of the IOR in France is a positive sign of policymaking addressing the issue of PO. The statement that the IOR will be supplemented or replaced in 2024 by a durability index that accounts for the reliability of the product further details such a vision. Assessing both repairability and reliability can support mitigating planned obsolescence because it directly considers the product longevity.

The current IOR pose some limitations to assess repairability encompassing hardware, firmware and software obsolescence. The iFixit IOR prioritises issues regarding hardware, thus providing a more accurate critique of product architecture decisions. In the French IOR, hardware repairability and software updates are two of the five categories. Nevertheless, even though a product can be easily disassembled and reassembled, its functionality can be limited or rendered obsolete by firmware. Such a condition is not addressed in any current IOR.

\section{CONCLUSION}

The paper unravels the evolution of the patterns of PO and the steps towards mitigating them from a practical perspective in the mobile phone industry. Technology obsolescence supersedes aesthetic obsolescence and entails additional complexity by encompassing issues related to hardware, firmware and software, as well as complementary practices limiting the user and third-party repairers' activities. One of the current limitations pointed out in this article lies in assessing the IOR mainly from a hardware perspective and not detailing how firmware must work in case of component replacement for not hindering functionality. This question requires further research to establish guidelines for manufacturers to enable repairability whilst still protecting sensitive personal data.

The strategic considerations that the Fairphone encapsulates and principles demanded by communitycentred organisations have been included in the French law analysed in this article, and the European Circular Economy Action Plan. If we consider that industrial design principles such as modularity and design for disassembly are not recent developments, then we can conclude that the mitigation of PO is a policymaking endeavour supported by industrial design knowledge and heuristics, among others.

The current reduced lifespan of smartphones comes at the expense of consumers and the environment. Social enterprises and grassroots movements advocating for a more sustainable system of production create a positive chain of events up to a certain extent. Nonetheless, challenges to the way the market operates require policymakers to establish predefined conditions for major industry players' practices. Only then, a fairer relationship between consumers, producers and the environment can be met.

\section{REFERENCES}

Apple. (2019), "Update your iPhone 5 to resume using App Store, iCloud, email, web, and other services", Apple Support, available at: https://support.apple.com/en-us/HT210712 (accessed 16 November 2020).

Bakker, C., Wang, F., Huisman, J. and den Hollander, M. (2014), "Products that go round: exploring product life extension through design", Journal of Cleaner Production, Vol. 69, pp. 10-16.

Bartels, B., Ermel, U., Pecht, M. and Sandborn, P. (2012), Strategies to the Prediction, Mitigation and Management of Product Obsolescence, John Wiley \& Sons, Ltd, Hoboken, N.J.

Bouwman, H., Carlsson, C., Carlsson, J., Nikou, S., Sell, A. and Walden, P. (2014), "How Nokia failed to nail the Smartphone market", presented at the 25th European Regional Conference of the International Telecommunications Society (ITS), Calgary: International Telecommunications Society (ITS), Brussels.

Cooper, T. (1994), Beyond Recycling: The Longer Life Option, New Economics Foundation, London.

Cooper, T. (2004), "Inadequate Life?Evidence of Consumer Attitudes to Product Obsolescence", Journal of Consumer Policy, Vol. 27 No. 4, pp. 421-449.

European Commission. (2020), Circular Economy Action Plan: For a Cleaner and More Competitive Europe, No. COM/2020/98, European Commission, Brussels, p. 28.

Forti, V., Baldé, C.P., Kuehr, R. and Bel, G. (2020), The Global E-Waste Monitor 2020: Quantities, Flows and the Circular Economy Potential, United Nations University (UNU), Bonn/Geneva/Rotterdam.

Go, T.F., Wahab, D.A. and Hishamuddin, H. (2015), "Multiple generation life-cycles for product sustainability: the way forward", Journal of Cleaner Production, Vol. 95, pp. 16-29.

GSMArena. (2000), “GSMArena.com”, available at: https://www.gsmarena.com/ (accessed 17 November 2020).

Huang, E.M. and Truong, K.N. (2008), "Breaking the disposable technology paradigm: opportunities for sustainable interaction design for mobile phones", Proceedings of the SIGCHI Conference on Human Factors in Computing Systems, ACM, New York, NY, USA, pp. 323-332.

iFixt. (2020), "iFixit: The Free Repair Manual”, available at: https://www.ifixit.com/ (accessed 12 November 2020). 
Joshi, S. and Pargman, T.C. (2015), "In search of fairness: critical design alternatives for sustainability", Proceedings of The Fifth Decennial Aarhus Conference on Critical Alternatives, Aarhus University Press, Aarhus, pp. 37-40.

King, A.M., Burgess, S.C., Ijomah, W. and McMahon, C.A. (2006), "Reducing waste: repair, recondition, remanufacture or recycle?", Sustainable Development, Vol. 14 No. 4, pp. 257-267.

Kozinets, R. (2009), Netnography: Doing Ethnographic Research Online, 1st edition., SAGE Publications Ltd, Thousand Oaks, CA.

Kuppelwieser, V.G., Klaus, P., Manthiou, A. and Boujena, O. (2019), “Consumer responses to planned obsolescence”, Journal of Retailing and Consumer Services, Vol. 47, pp. 157-165.

Lamberg, J.-A., Lubinaite, S., Ojala, J. and Tikkanen, H. (2019), "The curse of agility: The Nokia Corporation and the loss of market dominance in mobile phones, 2003-2013”, Business History, Routledge, available at:https://doi.org/10.1080/00076791.2019.1593964.

Lau, M.M., Lam, A.Y.C. and Cheung, R. (2016), "Examining the Factors Influencing Purchase Intention of Smartphones in Hong Kong”, Contemporary Management Research, Vol. 12 No. 2, available at:https://doi.org/10.7903/cmr.13836.

Lee, M.S. and Soon, I. (2017), "Taking a bite out of Apple: Jailbreaking and the confluence of brand loyalty, consumer resistance and the co-creation of value", Journal of Product \& Brand Management, Emerald Publishing Limited, Vol. 26 No. 4, pp. 351-364.

Lilley, D., Smalley, G., Bridgens, B., Wilson, G.T. and Balasundaram, K. (2016), "Cosmetic obsolescence? User perceptions of new and artificially aged materials", Materials \& Design, Vol. 101, pp. 355-365.

London, Bernard. (1932), Ending the Depression through Planned Obsolescence, New York, available at: https://catalog.hathitrust.org/Record/006829435 (accessed 13 November 2020).

Longmuss, J. and Poppe, E. (2017), "Planned Obsolescence: who are those planners?", in Bakker, C.A. and Mugge, R. (Eds.), PLATE: Product Lifetimes And The Environment: Conference Proceedings of PLATE 2017, 8-10 November 2017, Delft, the Netherlands, IOS Press.

Meloni, M., Souchet, F. and Sturges, D. (2018), Circular Consumer Electronics: An Initial Exploration, The Ellen MacArthur Foundation, available at: https://www.ellenmacarthurfoundation.org/assets/ downloads/CircularConsumer-Electronics-2704.pdf (accessed 16 November 2020).

Mikolajczak, C. (2020), “Apple crushes one-man repair shop in Norway's Supreme Court, after three-year battle”, Right to Repair Europe, 4 June, available at: https://repair.eu/news/apple-crushes-one-man-repair-shop/ (accessed 11 November 2020).

MTE. (2021), Instructions Manual for the Calculation of the Repairability Index of Electrical and Electronic Equipments, p. 16.

Packard, V. (2011), The Waste Makers, Reprint edition., Ig Publishing, New York.

Proske, M., Clemm, C. and Richter, N. (2016), Life Cycle Assessment of the Fairphone 2, Fraunhofer IZM.

Right to Repair. (2020), "Right to Repair", Right to Repair Europe, available at: https://repair.eu/ (accessed 12 November 2020).

Sandborn, P. (2007), "Software Obsolescence - Complicating the Part and Technology Obsolescence Manage-ment Problem", IEEE Trans on Components and Packaging Technologies, Vol. 30 No. 4, pp. 886-888.

Sloan, A. (1990), My Years with General Motors, Reissue edition., Currency, New York.

Statista. (2018), "iPhone sales by year", Statista, available at: https://www.statista.com/statistics/276306/globalapple-iphone-sales-since-fiscal-year-2007/ (accessed 11 November 2020).

Sumter, D., Bakker, C.A. and Balkenende, A.R. (2017), "The role of product designers in the transition towards the circular economy: A reality check", Plate Product Lifetimes And The Environment 2017, IOS Press, Vol. 9, available at:https://doi.org/10.3233/978-1-61499-820-4-391.

Sumter, D., de Koning, J.I.J.C., Bakker, C.A. and Balkenende, A.R. (2020), “Circular economy competencies for design”, Sustainability, Vol. 12 No. 4, available at:https://doi.org/10.3390/su12041561.

Sun, Y., Kong, L., Khan, H.A. and Pecht, M.G. (2019), "Li-ion Battery Reliability - A Case Study of the Apple iPhone®", IEEE Access, presented at the IEEE Access, Vol. 7, pp. 71131-71141.

Toufani, S., Stanton, J.P. and Chikweche, T. (2017), “The importance of aesthetics on customers' intentions to purchase smartphones", Marketing Intelligence \& Planning, Emerald, Vol. 35 No. 3, pp. 316-338.

Verganti, R. (2011), "Radical Design and Technology Epiphanies: A New Focus for Research on Design Management”, Journal of Product Innovation Management, Vol. 28 No. 3, pp. 384-388.

Webster, K., MacArthur, D.E. and Stahel, W. (2017), The Circular Economy: A Wealth of Flows, Ellen MacArthur Foundation Publishing, Cowes.

Wernink, T. and Strahl, C. (2015), "Fairphone: Sustainability from the Inside-Out and Outside-In”, in D’heur, M. (Ed.), Sustainable Value Chain Management: Delivering Sustainability Through the Core Business, Springer International Publishing, Cham, pp. 123-139.

Wolk, M.H. (2010), “The iPhone Jailbreaking Exemption and the Issue of Openness", Cornell Journal of Law and Public Policy, Vol. 19 No. 3, p. 35.

Yin, R.K. (1994), Case Study Research: Design and Methods, 2nd ed., Sage, Thousand Oaks, London, New Delhi. 